\title{
Derechos y Culturas. Los retos de la diversidad en el espacio público y privado
}

\author{
Ángeles Solanes Corella \\ (2018), Tirant lo Blanch \\ Valencia (España), 488 pp.
}

\author{
José María Garrán Martínez \\ Universidad de Salamanca \\ garran@usal.es
}

\section{DOI: https://doi.org/10.20318/eunomia.2019.4714}

El trabajo que presenta la profesora Ángeles Solanes responde esencialmente a un triple análisis: "observar la realidad, analizarla y aprehender los retos que plantean las actuales barreras para la convivencia en perspectiva jurídico-política", responder, en último término, a "los retos de la diversidad en el espacio público y en el privado".

El trabajo se abre con el prólogo del profesor Javier de Lucas, en el que se subrayan los valores del libro y se procede a su contextualización, al señalar que la autora "nos plantea el examen de conflictos relacionados con la copresencia en un mismo espacio de soberanía -en el sentido sobre todo jurídico- de diferentes culturas, en plural. Esto es, rompe con el prejuicio habitual de que los conflictos que vivimos suponen un enfrentamiento binario, casi maniqueo: de una parte, nuestros valores (los buenos, los verdaderos, los que han hecho posible la democracia y los derechos humanos), frente -de otro lado- a los disvalores que nos amenazan con la llegada de los que vienen de fuera. Ese planteamiento ignora que en nuestro lado hay también pluralidad, diversidad e incluso cada vez más en la medida en la que la democracia estimula el desarrollo de la libertad: no existe una cultura española, para decirlo claro y de una vez. La nuestra, la sociedad de acogida, es plural a su vez. Y, por supuesto, frente a esa ficción de que lo que llega con los flujos migratorios es homogéneo (un mixtum islamo/árabe/africano, que de suyo ya constituye un disparate), lo cierto es que nos llegan diferentes culturas. Y lo más importante, que en el contacto, en el intercambio, todos nos transformamos, aumentado así la pluralidad, la diversidad".

Prólogo que finaliza fijando el sentido de la obra de la profesora Solanes como respuesta a una realidad vertebrada por la diversidad ya que "nos encaminamos hacia sociedades en que la diversidad se transforma en mestizaje y eso lo encarnan, aquí sí que hay que devolverles la centralidad, los inmigrantes asentados, esos vecinos que, si sabemos ayudar a convertir en nuevos ciudadanos, nuevos titulares de una ciudadanía de raíces y perfiles mestizos, pueden ser una potente palanca transformadora". 
Al prólogo le siguen cinco capítulos: el primero es una introducción; el segundo se dedica a la libertad y a la igualdad en sociedades multiculturales; el tercero plantea los retos de la diversidad cultural en el espacio público; el cuarto analiza los retos de la diversidad cultural en el espacio privado y finaliza con un quinto capítulo en el que se realizan una serie de reflexiones finales.

En la Introducción la autora asume un sentido amplio de la diversidad cultural, aprehendiendo factores como el lingüístico, el étnico, el nacional, el religioso o el identitario que dan lugar al desarrollo de grupos sociales diversos que pretenden proyectar sus diferencias en el espacio público y conservarlas en el privado, remarcando que las políticas públicas de gestión de la diversidad han de incorporar un enfoque transversal de género.

La noción de conflicto, concebida por Ángeles Solanes como las desavenencias que se dan al intentar encontrar formas de conciliar, en palabras de Parekh, las reivindicaciones legítimas de unidad y diversidad para lograr unidad política sin uniformidad cultural, han de ser inclusivas sin ser asimilacionistas y cultivar un sentido de pertenencia respetando las legítimas diferencias culturales. Tal perspectiva conceptual exige revisar las nociones de libertad e igualdad en las sociedades multiculturales. Pasa posteriormente la autora a seleccionar los aspectos claves para la gestión de los conflictos que plantea la diversidad cultural en la dimensión pública y privada, sin desatender a la realidad española, desde la regulación normativa hasta la jurisprudencia nacional y europea. Ya al final de la introducción anticipa una serie de propuestas que, más que conclusiones, son ideas para establecer políticas proactivas de la diversidad desde la neutralidad del Estado, con el objetivo de conseguir una sociedad que apueste por el reconocimiento, la representación y la redistribución ( $3 \mathrm{R})$ en aras de una convivencia que suponga más que la mera coexistencia.

En el Capítulo 2, la profesora Ángeles Solanes considera que la necesidad de modular los marcadores primarios de identidad (tales como la lengua, la religión, las tradiciones, los valores y las diferentes prácticas que se aúnan bajo la idea de cultura), conjugándolos con la dimensión garantista de los derechos humanos, es uno de los retos que deben abordar las políticas de gestión de la diversidad. Así lo evidencia la autora al revisar la conexión entre derechos humanos, cultura e identidad, al analizar la integración desde la desigualdad material y la necesidad de construcción de un marco de referencia compartido.

Tales parámetros requieren una atención crítica acerca del alcance de la libertad y la igualdad entendidas como valores, principios, derechos y metaderechos. La libertad, negativa y positiva, expresa y realiza el valor moral de la autonomía personal, tomando en consideración el límite de la libertad ajena, pero, además, en su dimensión material exige del Estado los medios que permitan, tanto a los individuos como a los grupos culturales, dotar de contenido otras libertades.

Entre las diferentes propuestas que se estudian una es la articulación del modelo de igual valoración jurídica de las diferencias, ya que ésta permite la consecución de políticas públicas que favorezcan las denominadas $3 \mathrm{R}$.

Adoptar este enfoque exige fijar la noción de cultura por la que se opta y, en este sentido, la autora alude a un sistema de creencias, valores, costumbres y conductas, que los miembros de una sociedad utilizan, que son transmitidos entre generaciones a través del aprendizaje y que tiene un carácter histórico, complejo y dinámico. La interacción entre diferentes culturas es uno de los aspectos fundamentales en la trasformación cultural, aunque no sea fluida ni pacífica, siendo 
en este contexto donde hay que ubicar la convivencia desde la libertad y la igualdad. Cuando determinados grupos se sienten amenazados en su especificidad, se activa esa idea de pertenencia a la que la identidad cultural hace referencia. La construcción identitaria revela también la estratificación social y la imposibilidad para determinadas personas de reivindicar una identidad distinta de la clasificación que le es impuesta.

Este pormenorizado análisis que realiza Ángeles Solanes le lleva a considerar que es fundamental evitar dos confusiones. El primer lugar, es erróneo no distinguir entre los casos en que las reivindicaciones para proteger la identidad cultural afectan a bienes y valores que pueden considerarse sacrificables atendiendo a las normas del sistema legal del Estado, de aquellos otros supuestos en que el reconocimiento de dichas diferencias culturales puede resultar realmente problemático o incompatible con la protección de los derechos fundamentales y humanos y, por tanto, con las exigencias del Estado democrático de Derecho. En segundo lugar, otra incorrección sería no delimitar el papel que efectivamente juegan las diferencias culturales para determinar o agravar cualquier conflicto social. Se hace necesario, en consecuencia, establecer si en determinados conflictos y tensiones la diversidad cultural es especialmente significativa o si, por el contrario, se apela a ella de forma equívoca porque lo que existe es una desigualdad manifiesta producto de una injusta redistribución.

Se ponen de manifiesto los riesgos que la defensa cultural puede conllevar, frente a la cual, desde las reglas del Estado democrático de Derecho, hay que insistir en que la interpretación y la aplicación de las normas deben obedecer a criterios preventivos, con independencia de sus destinatarios, atendiendo al bien común y al interés superior. La desconfianza entre diferentes grupos que se caracterizan por identidades claramente definidas, potencia la asociación entre una determinada identidad cultural y comportamientos socialmente peligrosos vistos como amenazas, hace que el ordenamiento jurídico introduzca medidas que pueden generar situaciones de desigualdad, y aviva discursos que, frente a la presencia de grupos culturalmente diversos asociados a la extranjería, apuesten por pasar de la integración cívica a una actitud de rechazo al inmigrante.

En los distintos retos que se analizan en este trabajo la relación entre la cultura, la identidad y la autonomía individual adquiere especial importancia cuando se conjuga con el ejercicio de la libertad y la igualdad, y en concreto, con el respeto de derechos como la libertad de pensamiento, conciencia y religión. Por tanto, es ineludible gestionar la diversidad otorgándole un lugar compatible con el respeto y la garantía de los derechos humanos.

La autora ilustra las tensiones aludidas abordando los principales conflictos en España y cómo han sido resueltos a nivel supranacional desde el punto de vista jurisprudencial en el Capítulo 3. El análisis se centra en las tensiones que aparecen en la dimensión pública, esto es en el uso del espacio público y en el contexto de las sociedades multiculturales, especialmente los que han suscitado importantes desacuerdos, tales como: la utilización de símbolos de pertenencia y el uso del espacio público, los límites de las prácticas alimentarias religiosas y por convicción, y la ubicación de los lugares de culto y los cementerios.

En relación a los símbolos de pertenencia, se refiere a la disputa sobre el velo islámico integral, pero también con el no integral. En España el intento de establecer una normativa prohibitiva del velo integral fue frenado por la jurisprudencia.

En este trabajo se analiza la paradigmática sentencia del Tribunal Europeo de Derechos Humanos de 1 de julio de 2014, en el caso S.A.S. contra Francia, a 
propósito de la ley francesa que prohíbe la ocultación del rostro en el espacio público. En ella, el Tribunal avala esta prohibición a partir de la noción de convivencia, entendida como la interacción de los individuos en el espacio público, en la que el rostro juega un papel fundamental. Deja así un amplio margen de discrecionalidad al Estado. El Tribunal descarta el ataque al principio de igualdad y no discriminación y la necesidad de proteger la seguridad. Se hace así hace prevalecer, de modo muy cuestionable como destaca Ángeles Solanes, la noción de convivencia, no reconocida en el Convenio Europeo de Derechos Humanos, frente al artículo 9 del mismo que protege la libertad religiosa.

Respecto a los velos no integrales, se recuerda que en la jurisprudencia del Tribunal Europeo de Derechos Humanos existe una larga tradición de prohibición, especialmente en el ámbito educativo (asuntos Lucia Dahlab contra Suiza, Leyla Sahin contra Turquía, Kervanci contra Francia y Dogru contra Francia). En general, España es uno de los ejemplos de no prohibición del uso de vestimenta religiosa en los colegios, salvo casos puntuales como el del centro Camilo José Cela, recogido en la Sentencia del Tribunal Superior de Justicia de Madrid de 8 de febrero de 2013. La autora estudia también los ámbitos laboral y penitenciario.

En cambio, en lo que atañe a los símbolos religiosos estáticos en el espacio público, la autora evidencia cómo la jurisprudencia española ha sido más unánime al considerar dichos símbolos como culturales, sin entender que conculcan el principio de aconfesionalidad.

Tratándose también de símbolos religiosos estáticos, se menciona un tema cuyo análisis exhaustivo, como se reconoce expresamente, supera las posibilidades de esta obra pero que, es imprescindible: la Ley de Memoria Histórica. Dicha norma recoge, en sus artículos 15, 16 y en la Disposición Adicional Sexta, referencias a los símbolos franquistas que afectan a los símbolos religiosos cuando tienen la forma de cruces. En estos supuestos, también se ha avalado el hecho de que símbolos como la cruz puedan ser considerados de carácter cultural, pero que hayan perdido ese carácter de "exaltación" al que se refiere la mencionada norma y que, por tanto, no proceda la retirada de los mismos.

El espacio público es el marco donde pueden suscitarse tensiones relativas a la utilización de la vía pública para la realización de actividades culturales. Cuando se trata de grupos minoritarios hay dos elementos fundamentales para que esas actividades se realicen en la vía pública: el deseo de visibilización pública y la voluntad de reconocimiento social.

El segundo de los conflictos en el espacio público hace referencia a las prácticas alimentarias religiosas y por convicción en centros públicos como los colegios, los hospitales, los centros penitenciarios y de internamiento de extranjeros. Respecto a esta cuestión, no existe una obligación normativa al respecto, sino más bien una declaración de intenciones. Esa ausencia ha hecho que las solicitudes planteadas por las diferentes confesiones religiosas no hayan sido atendidas argumentado diferentes razones. Entre ellas, el desproporcionado nivel de exigencia y diferenciación en el uso de los servicios públicos, que no sería acorde con la racionalidad y con la limitación que tienen los fondos públicos. Como se evidencia en este trabajo, este tipo de argumentos no son sostenibles.

En dichos términos se ha pronunciado la jurisprudencia del Tribunal Europeo de Derechos Humanos, que entiende que no puede otorgarse mayor valor a argumentos de índole material que a la realización de los derechos de libertad religiosa, de conciencia y de pensamiento (caso Jakóbski contra Polonia, de 7 de 
diciembre de 2010). El Tribunal busca el equilibrio entre el derecho a una dieta determinada, como demanda razonable, y las limitaciones a las que tiene que hacer frente la administración en el caso de personas en situación de reclusión (asunto Vartic contra Rumania, de 17 de diciembre de 2013).

La jurisprudencia de los tribunales españoles ha actuado en sentido inverso a la europea. En el caso de los centros educativos, por ejemplo, el Tribunal Superior de Justicia de Madrid, en sentencia de 16 de junio de 2015, consideró que el servicio de comedor en las escuelas es voluntario. Por ello, atendiendo a la racionalidad, la proporcionalidad y el respeto a terceros, no puede considerarse que la libertad religiosa deba llevarse al extremo de exigir que el servicio público articule una organización individualizada. En relación a los centros penitenciarios, se ha justificado la falta de un menú específico vegetariano por considerarlo innecesario.

Dado que en España estas situaciones se darán con más frecuencia, la autora procede a puntualizar algunas cuestiones. Lo fundamental, en estos casos, es asegurar un mínimo coherente con una concepción de la igualdad entendida como igualdad de recursos, en el sentido que señala Dworkin. Aquello que exceda el mencionado principio podría entenderse como un coste de oportunidad que cada individuo debe concebir en relación con su capacidad de autodeterminación, que se traduce en aspiraciones y prioridades. Se trata de buscar así un equilibrio entre libertad y responsabilidad. En líneas generales, el mandato dirigido a las autoridades no contiene una obligación de resultado, pero la situación de sujeción no voluntaria, en los casos de privación de libertad y, además, de especial dificultad, en la que se encuentra los sujetos, deberían ser tomadas en consideración. Como se pone de manifiesto en las diferentes guías de buenas prácticas analizadas en el trabajo presentado, para que se incluyeran menús que respetaran los preceptos confesionales, sería necesario tomarlos en consideración en los pliegos de cláusulas contractuales que negocia la administración.

Un tercer conflicto que reclama también la supervisión legal y jurisprudencial, es el relativo a la distribución del suelo en el espacio público compartido, en el que los diferentes grupos religiosos se visibilizan y han de normalizar su presencia. En España se han suscitado diferentes problemas en torno a la ubicación de mezquitas, oratorios y otros lugares de culto. De la conjunción del artículo $16 \mathrm{CE}$, con otros preceptos constitucionales como los artículos 9.2,13.1, 14 y 47, se concluye que la utilización del suelo, para la ubicación de lugares de culto y cementerios, tiene influencia sobre el efectivo ejercicio y garantía del derecho fundamental de libertad religiosa. Desde la perspectiva de la legislación urbanística, los centros religiosos tienen la consideración de equipamientos comunitarios.

La autora apuesta por los denominados espacios multiconfesionales o centros pluriconfesionales. Estos equipamientos religiosos tendrían la ventaja de ser propiedad de la administración pública de tal forma que esta sería la encargada de su construcción, mantenimiento y conservación. De esta manera, se posibilitaría el ejercicio de la libertad religiosa en condiciones de igualdad por parte de creyentes de distintas confesiones, garantizándoles un lugar donde poder realizar los actos religiosos. Según la autora, en el caso español y a tenor de los conflictos analizados, se concluye la necesidad imprescindible de actualizar la legislación nacional y armonizar la de las diferentes Comunidades Autónomas para evitar desigualdades manifiestas.

En el Capítulo 4 se abordan los retos en el ámbito privado, específicamente aquellos que se ubican en el derecho de familia, en el contexto de la institución del matrimonio, dado que la familia es un espacio aglutinador del encuentro intercultural 
entre formas de vida familiar procedentes de círculos culturales, religiosos, sociales y jurídicos muy alejados.

Un primer conflicto que se estudia es el referido al matrimonio islámico, especialmente a los requisitos que son necesarios para que se reconozca efectos civiles en el ordenamiento jurídico español. Las instituciones islámicas vinculadas al matrimonio que mayores inconvenientes generan en España son la poligamia y el repudio. Ambas se dan, respectivamente, en el momento de la constitución y la disolución del vínculo matrimonial.

El segundo de los conflictos en el ámbito privado se mantiene en el marco de la institución matrimonial, abordando el estudio del matrimonio de conveniencia, forzado e infantil, estos dos últimos desde una perspectiva penal. En el matrimonio de conveniencia, caracterizado por el abuso y fraude de ley que subyace, se incluyen aquellas uniones celebradas con la única finalidad de regularizar la situación en España de uno de los contrayentes, mediante el matrimonio con español o con quien ya se encuentra legalmente en el país.

En el caso de los matrimonios forzados se alude a la unión de dos personas en la que al menos una de ellas no ha dado su libre y pleno consentimiento para contraer matrimonio. La característica fundamental de estos matrimonios es el uso de la violencia física y psíquica para doblegar la voluntad y obligar al menos a una de las partes a la unión. Los matrimonios forzados son una de las múltiples manifestaciones de la violencia hacia las mujeres que tiene su origen común en las desigualdades de género $y$, además, ahondan en el debate sobre su autonomía y las características del consentimiento libre. Este estudio profundiza en la compleja delimitación entre matrimonios pactados y matrimonios forzados, dado que estos últimos pueden ser inicialmente matrimonios concertados en origen y viceversa. Tampoco puede pasarse por alto, en ocasiones, su conexión con otros delitos como la trata de seres humanos.

En estrecha conexión con este supuesto se aborda el caso de los matrimonios infantiles. Dicho matrimonio hace referencia a aquel en el que al menos uno de los contrayentes es un niño, entendiendo por tal al menor de 18 años, salvo que, en virtud de la ley que le sea aplicable, haya alcanzado antes la mayoría de edad. El análisis de diferentes resoluciones de Naciones Unidas y del Consejo de Europa, pone en evidencia la necesidad de articular políticas y legislaciones para poner fin a estos matrimonios. Para ello es necesaria la colaboración de las comunidades que los practican.

En España el matrimonio infantil aparece regulado en el artículo $172.3 \mathrm{CP}$ como un tipo cualificado agravado del matrimonio forzado, sin embargo, esta precisión de la reforma de 2015 sería mejorable a juicio de la profesora Ángeles Solanes.

El último de los conflictos que se estudian son los denominados crímenes de honor. La autora señala que el concepto de honor tiene una dimensión colectiva o grupal, más que estrictamente individual, y va unido a lo que podrían considerarse culturalmente los códigos de honor. Desde Naciones Unidas se insiste en la necesidad de que la legislación incluya una definición amplia de crímenes de honor que abarque todos los actos de discriminación y violencia para preservar el honor de la familia. Las diferentes resoluciones y recomendaciones de la Asamblea General de Naciones Unidas, los instrumentos internacionales como la CEDAW y el Convenio de Estambul, establecen estándares específicos que marcan la actuación de los Estados miembros para la prevención, prohibición y erradicación de dichas prácticas. 
El Tribunal Europeo de Derechos Humanos se ha ocupado de algunos supuestos relacionados con los crímenes de honor a propósito de asuntos vinculados a la violencia doméstica (como en el caso Opuz contra Turquía, de 9 de junio de 2009) y a las expulsiones (como en la sentencia N. contra Suecia, de 20 de julio de 2010).

España no cuenta con una normativa concreta que se ocupe de los crímenes de honor, sino que esta práctica queda subsumida dentro de la violencia de género y se reconduce a diferentes tipos de delitos.

El libro se cierra con el Capítulo 5 en el que se procede a realizar una serie de reflexiones por parte de la profesora Ángeles Solanes, indicando que en el espacio público concurre un objetivo central para las democracias pluralistas, que no es otro que evitar que la diversidad cultural se convierta en distinción social y surjan nuevas formas de desigualdad. Ese objetivo persiste en el ámbito privado, especialmente en la institución del matrimonio. Para poder afrontar y gestionar estas desavenencias, es imprescindible el reconocimiento, la redistribución y la representación, desde la neutralidad del Estado. Por eso, abordar la gestión de la diversidad cultural es, en el fondo, una cuestión de igualdad y de simetría en el poder social. Este libro invita a reflexionar críticamente, desde el análisis riguroso, sobre los diferentes retos señalados, ofreciendo alternativas trasladables a políticas públicas para la construcción de un marco común compartido desde los derechos humanos y la interculturalidad. 